\title{
Bainite Formation in Medium-Carbon Low-Silicon Spring Steels Accounting for Chemical Segregation
}

\author{
C. GOULAS, M.G. MECOZZI, and J. SIETSMA
}

In this paper, the effect of chemical inhomogeneity on the isothermal bainite formation is investigated in medium-carbon low-silicon spring steel by dilatometry and microscopy. The analysis of the microstructure at different times during transformation shows that chemical segregation of substitutional alloying elements resulting from casting strongly affects the bainite formation by retarding the transformation kinetics and limiting the maximum achievable bainite fraction. During holding at temperatures close to and above the martensite start temperature, a homogeneous lower bainitic microstructure can be eventually obtained, whereas at higher temperatures, incomplete bainitic reaction is evident. It was also found that at the early stages of the transformation, differences in the bainite formation kinetics, due to local inhomogeneities in $\mathrm{Cr}$ and $\mathrm{Mn}$ concentration, result in retardation of the growth of bainite in the high $\mathrm{Mn}$ and $\mathrm{Cr}$ concentration regions. The calculated difference in driving force for nucleation between the enriched and the depleted areas is not by itself sufficient to explain the microstructures obtained and thus significant influence of growth on bainite formation is observed. Particularly, it was calculated and experimentally observed that $\mathrm{Cr}$ partitions in the carbides in the high $\mathrm{Mn}, \mathrm{Cr}$ regions during the isothermal treatment, limiting the transformation kinetics.

DOI: $10.1007 / \mathrm{s} 11661-016-3418-6$

(C) The Author(s) 2016. This article is published with open access at Springerlink.com

\section{INTRODUCTION}

IN the past decades, the continuous market demand for improving vehicle performance and the rising awareness about $\mathrm{CO}_{2}$ emission and energy consumption created the need to develop new, more energy efficient production processes that include commonly used heat treatments. To reduce the overall weight of vehicles, the automotive industry needs to focus on each individual component. This research is related to the definition of alternative heat treatments to produce automotive springs. Low-alloyed, medium- or high-carbon steels are the most commonly used materials for automotive spring production. Recently, research on spring steels started to concentrate on springs with bainitic microstructures, instead of the commonly used tempered martensitic microstructures. Bainitic microstructure offers in principle significant advantages over the most commonly used tempered martensite. First of all, it offers a fine microstructure with high strength and acceptable ductility. The fully bainitic microstructure has a lower crack growth rate than tempered martensite.

C. GOULAS, Ph.D. Candidate, is with the Materials innovation institute (M2i), Electronicaweg 252628 XD Delft, The Netherlands, and also with Department of Materials Science and Engineering, Delft University of Technology, Mekelweg 2, 2628 CD Delft, The Netherlands. Contact e-mail: k.goulas@tudelft.nl M.G. MECOZZI, Senior Postdoctoral Researcher, and J. SIETSMA, Full Professor, are with the Department of Materials Science and Engineering, Delft University of Technology.

Manuscript submitted May 18, 2015.

Article published online March 9, 2016
Tomita and Okabayashi showed that lower bainite exhibits increased fracture ductility and notch toughness, because micro-crack propagation is effectively inhibited by the fine bainitic ferrite plate morphology. ${ }^{[1]}$ The bainitic microstructure, containing fine and evenly dispersed hard cementite precipitates, can be expected to effectively retard the fatigue crack growth by crack interlocking. ${ }^{[2]}$ Additionally, during processing, the tempering treatment can be avoided, which is an indispensable and costly step of the tempered martensite production. In this way, temper embrittlement is avoided as well and a lower energy amount is needed for the heat treatment.

Although bainite and its advantages have been known for decades, the incomplete understanding of the influence of chemical composition and process parameters on the resulting bainite fraction and morphology limits the industrial development of bainitic steels. For almost a century, a large body of research has been done on the bainite reaction and two conflicting ideas about mechanism of formation of bainite have been developed. When formed at low temperatures, bainite looks like martensite and it is sometimes even impossible to distinguish them microscopically. This experimental finding suggests that the mechanism of formation of bainite is similar to that of martensite and therefore is diffusionless in nature. On the other hand, an increasing number of experimental and theoretical studies support the similarity between bainitic ferrite and proeutectoid ferrite with Widmanstätten morphology and the idea that bainite grows under carbon diffusion. Hultgren first proposed in 1947 that upper bainite could form by initial Widmanstätten ferrite formation, with subsequent 
precipitation of cementite on its sides. ${ }^{[3]}$ The concept was further analyzed by Hillert, who has shown that there is no reason to treat Widmanstätten ferrite and bainitic ferrite as different products, as there is no kinetic discontinuity. ${ }^{[4]}$ According to this approach, the bainitic ferrite nucleates at austenite grain boundaries and grows at a rate determined by the diffusivity of carbon. Aaronson et al., supporting the above-described theory, have considered the effect of alloying elements on the bainitic transformation, and the potential segregation of substitutional elements at the growing phase interface. ${ }^{[5]}$ The incomplete reaction phenomenon, described as the premature cessation of bainite formation before the equilibrium fraction of this phase is attained, is explained by the solute drag effect that significantly retards the growth of the bainitic ferrite. ${ }^{[6-8]}$

The diffusionless approach was introduced by Zener in $1946^{[9]}$ further developed by Ko and Cottrell, ${ }^{[10]}$ and more recently supported by Bhadeshia. ${ }^{[1]}$ According to this approach, a sub-unit of bainitic ferrite, supersaturated in carbon, nucleates on an austenite grain boundary. The growth is practically instantaneous and displacive and stops because of the plastic deformation of the adjacent austenite. After growth stops, carbon is rejected from the supersaturated ferrite by diffusion into the residual austenite, in which it can form carbides with para-equilibrium composition. Carbon can also directly precipitate in the form of carbides within the bainitic ferrite sub-unit, if insufficient diffusion can take place due to the transformation temperature being low. Once bainitic sub-units have formed, the bainite formation can continue by the autocatalytic nucleation and displacive growth of new sub-units on the tip of previously formed sub-units. Bainitic transformation can be incomplete if carbide precipitation is inhibited. This implies that the austenite is gradually enriched in carbon and is eventually stabilized at the given temperature. In this case, according to Zener, diffusionless growth would cease when the carbon content of the residual austenite reaches a value, for which at the given temperature, ferrite and austenite have the same Gibbs free energies. These points form a curve, which was later named " $T_{0}$ curve." ${ }^{[12]}$ It has also been proposed that the line of equal Gibbs free energy of austenite and ferrite should be calculated with an additional term for ferrite due to the strain energy in the untransformed austenite. Therefore the maximum carbon content for diffusionless growth should differ from the value predicted by the $T_{0}$ curve. Bhadeshia estimated the driving force for diffusionless growth at experimental bainite start temperature equal to $400 \mathrm{~J} / \mathrm{mol}^{[12]}$ The calculated curve with $400 \mathrm{~J} / \mathrm{mol}$ of additional energy in ferrite was denoted with $T_{0}{ }^{\prime}$ curve.

The role of carbon and substitutional alloy elements in the bainite formation is described differently within the two competitive schools of thought. This makes the design of bainitic treatments on industrial scale a very challenging task, especially in the presence of compositional inhomogeneity in the industrial steel product.

One source of compositional inhomogeneity in steel is the microsegregation of alloy elements during the solidification process, when the liquid, present in the interdendritic spaces, becomes enriched of alloy elements, such as manganese, chromium, silicon, molybdenum, and phosphorous, and the dendrites cores become depleted of these solute elements. After solidification, there are regions with low and high solute element concentrations in austenite. Hot rolling transforms these regions into parallel layers in which austenite exhibits different transformation kinetics to allotriomorphic and Widmanstätten ferrite, pearlite, bainite, or martensite. This can determine the formation of a laminated microstructure, called banding.

In the present study, we will explore the microstructure evolution of hot-rolled $51 \mathrm{CrV} 4$, in case a subsequent isothermal bainitic treatment is applied. The effect of compositional inhomogeneity on the bainite formation kinetics is analyzed. Interrupted dilatometry tests, microscopy and thermodynamic calculations help to monitor and explain the segregation-induced differences in the formation of bainite at different temperatures.

\section{EXPERIMENTAL PROCEDURE}

Samples of 51CrV4 steel with chemical composition shown in Table I were received in the as-rolled condition. The samples were cut out of hot-rolled bars with dimensions $95 \times 49 \times 5500 \mathrm{~mm}^{3}$. The chemical analysis was performed on $30 \times 30 \mathrm{~mm}^{2}$ cross-sections of the bars, transverse to the rolling direction, by means of optical emission spectroscopy (OES). Dilatometric cylindrical specimens were machined using wire electro-discharge machining (EDM) with dimensions $\Phi 4 \times 10 \mathrm{~mm}^{2}$. EDM was used to assure that the dimensions have low tolerance and at the same time the initial microstructure remains intact.

The dilatometric tests were performed in a Bähr 805A Quench dilatometer. This instrument uses an induction coil to heat the sample and detects the length change of the sample with a linear variable displacement transducer (LVDT). The specimens were placed in the dilatometer with a thermocouple spot welded at the middle in order to control the temperature. Experiments with two thermocouples were also performed, one at the edge and the second at the middle in order to check the temperature gradient and whether the transformations occur evenly in the whole sample. In all experiments, the temperature differences recorded by the two thermocouples were within $10 \mathrm{~K}\left(10^{\circ} \mathrm{C}\right)$.

All samples were heated within 60 seconds to the austenitization temperature, $1173 \mathrm{~K}\left(900{ }^{\circ} \mathrm{C}\right)$, under vacuum and then quenched to an isothermal holding temperature in the range from $573 \mathrm{~K}$ to $783 \mathrm{~K}\left(300^{\circ} \mathrm{C}\right.$ to $510{ }^{\circ} \mathrm{C}$ ) using Helium $(\mathrm{He})$ gas. The quenching rate was high enough to avoid austenite-ferrite transformation according to CCT diagrams for the specific chemical composition. This rate was chosen to be $30 \mathrm{~K} / \mathrm{s}$

Table I. Chemical Composition of the 51CrV4 Grade as Measured by Optical Emission Spectroscopy

\begin{tabular}{lccccc}
\hline Elements & $\mathrm{C}$ & $\mathrm{Mn}$ & $\mathrm{Si}$ & $\mathrm{Cr}$ & $\mathrm{V}$ \\
\hline Wt pct & 0.51 & 1.02 & 0.33 & 1.15 & 0.12 \\
\hline
\end{tabular}


Table II. Time and Temperature Conditions for the 51CrV4 Dilatometric Tests

\begin{tabular}{|c|c|}
\hline Temperature $\mathrm{K}\left({ }^{\circ} \mathrm{C}\right)$ & Time \\
\hline $573(300)$ & $250 \mathrm{~s} 3600 \mathrm{~s}$ \\
\hline $693(420)$ & $125 \mathrm{~s} 2500 \mathrm{~s}$ \\
\hline $783(510)$ & $500 \mathrm{~s} 3600 \mathrm{~s}(80000 \mathrm{~s})$ \\
\hline
\end{tabular}

$\left(30{ }^{\circ} \mathrm{C} / \mathrm{s}\right)$. After the isothermal holding, the samples were quenched to room temperature. Interrupted treatments were performed on the basis of time intervals allowing the same volume fraction of bainite to be transformed for the different temperatures, as reported in Table II. The holding for 125 seconds at $693 \mathrm{~K}\left(420{ }^{\circ} \mathrm{C}\right)$ produces equivalent bainite fraction as the holding for 250 seconds at $573 \mathrm{~K}\left(300{ }^{\circ} \mathrm{C}\right)$. The same correspondence is obtained between the treatment for 250 seconds at $693 \mathrm{~K}\left(300{ }^{\circ} \mathrm{C}\right)$ and the treatment for 500 seconds at $573 \mathrm{~K}\left(300{ }^{\circ} \mathrm{C}\right)$.

Dilatometric curves were analyzed in order to evaluate the bainite formation at the different temperatures. For microstructural characterization, the dilatometric samples were mounted on a specially designed sample holder, then ground, polished, and etched with Nital 2 pct for 6 seconds. The specimens were examined by means of light optical microscopy for phase identification. For the analysis, an Olympus BX60M optical microscope was used.

For scanning electron microscopy (SEM) and scanning transmission electron microscopy-energy dispersive spectroscopy (STEM-EDS) analysis, specimens were prepared from the dilatometry samples. Even though the temperature gradient within the dilatometric specimen during the heat treatment was found to be within $10 \mathrm{~K}$, in order to ensure that the microstructure observations were consistent with the dilatometry measurements, the sample disks were cut from the middle zone of the dilatometric specimen. For SEM, the specimen was prepared following standard metallographic polishing procedure, and for STEM the disks were manually ground down to $60 \mu \mathrm{m}$, and then Ar ion was polished to final thickness using GATAN 691 PIPS system. For the SEM observation a Field Emission Gun (FEG)-SEM JEOL $6500 \mathrm{~F}$ operated at $15 \mathrm{kV}$ was employed, while for the STEM-EDS analysis, a JEM 2100 electron microscope operated at $200 \mathrm{kV}$ was used.

Finally, Electron Probe Micro Analysis was performed to evaluate alloying element segregation. The measurements were performed with a JEOL JXA 8900R microprobe using an electron beam with energy of $10 \mathrm{keV}$ and beam current of nominal $1000 \mathrm{nA}$ employing wavelength dispersive spectrometry (WDS). The points of analysis were located along a $500 \mu \mathrm{m}$ line with increments of $5 \mu \mathrm{m}$ and involved the elements $\mathrm{Mn}, \mathrm{Cr}, \mathrm{Si}$, and $\mathrm{V}$.

\section{RESULTS}

Figure shows the dilatometric curves obtained for treatments at different isothermal holding temperatures. It can be noticed in Figure 1(a) that as the isothermal holding temperature becomes higher, the relative

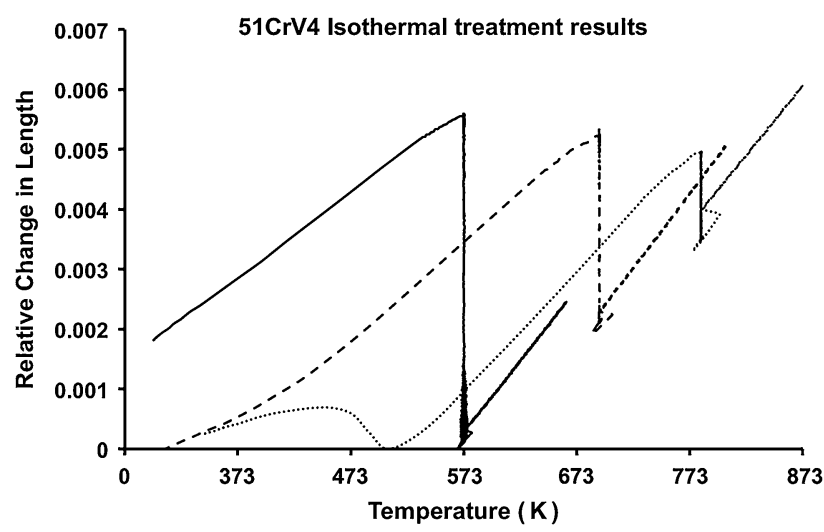

(a)

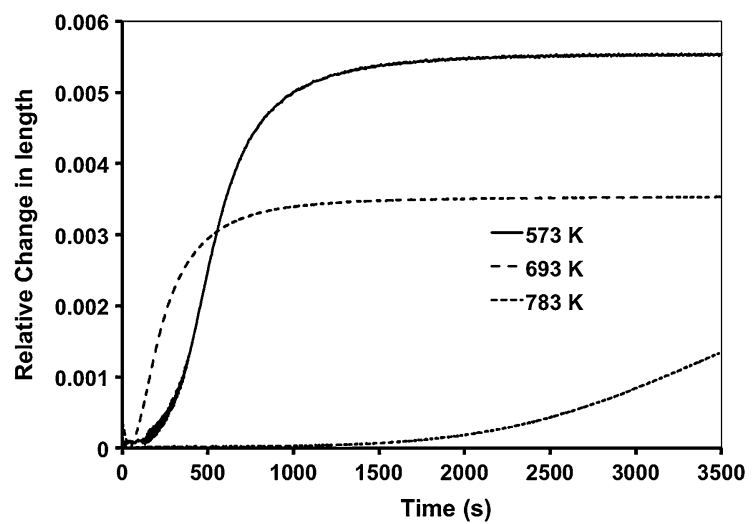

(b)

Fig. 1-Graphs of the cooling and isothermal holding segments of the dilatometric tests. (a) Relative change in length vs temperature, during the cooling part of the heat treatment. (b) Relative change in length $v s$ time, for isothermal holding at different temperatures.

dilatation during holding decreases. After the isothermal holding at $693 \mathrm{~K}, 783 \mathrm{~K}\left(420{ }^{\circ} \mathrm{C}, 510{ }^{\circ} \mathrm{C}\right)$, fresh martensite forms during the final quench, as shown by the deviation from the linearity of the dilatation curve. After isothermal holding at the lowest temperature, the dilatometric signal is linear during the final quench, indicating the absence of transformation in that segment. The artifact at the onset of the isothermal holding observed in the temperature monitoring of the treatments is caused by the shifting from the quenching stage to the isothermal stage, and was found to have no implication on the subsequent isothermal phase transformation. No ferrite was found to form at the prior austenite grain boundaries. In Figure 1(b), it can be seen that the bainite formation goes to completion within one hour for the lower two temperatures. During the isothermal holding at $783 \mathrm{~K}\left(510{ }^{\circ} \mathrm{C}\right)$, the dilatation is still increasing at the end of the experiment, but this change in length is attributed to a transformation product different than normal bainite/bainitic ferrite, as will be shown later.

From the samples used for the curves of Figure 1, only information about the final microstructure can be obtained. Interrupted heat treatment experiments were performed in order to follow the microstructure evolution. The samples that were heat treated in the 


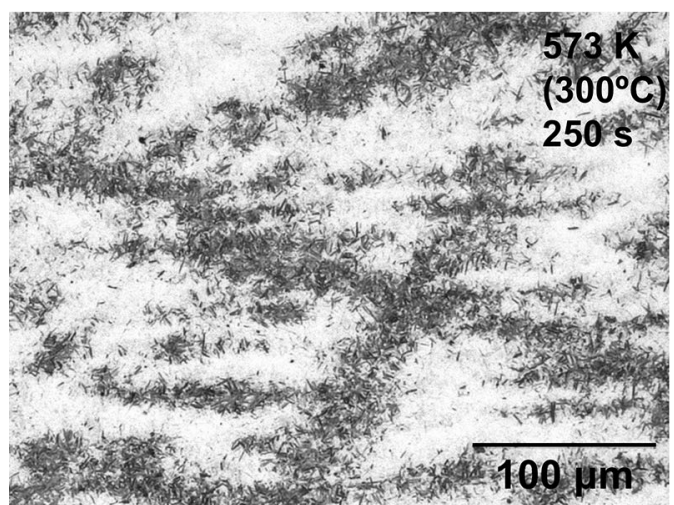

(a)

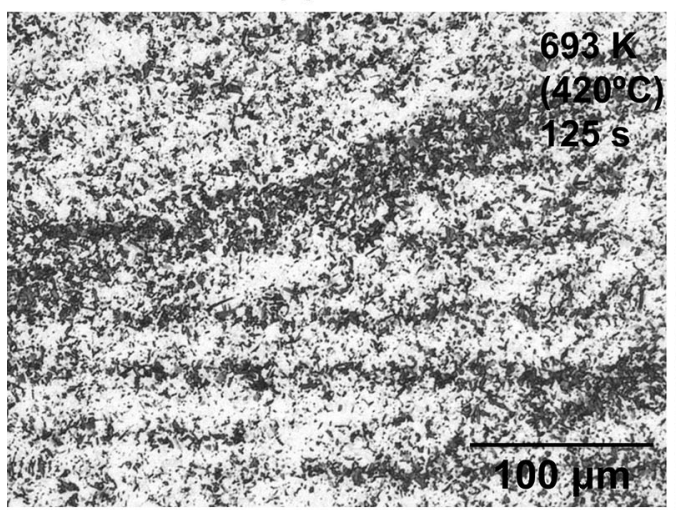

(c)

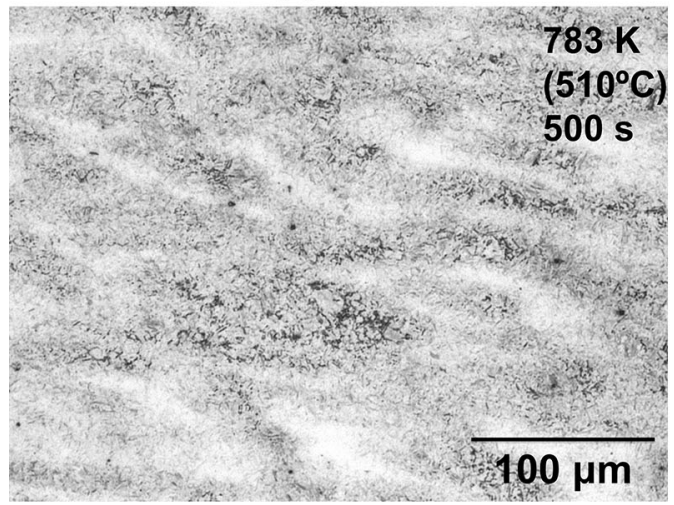

(e)

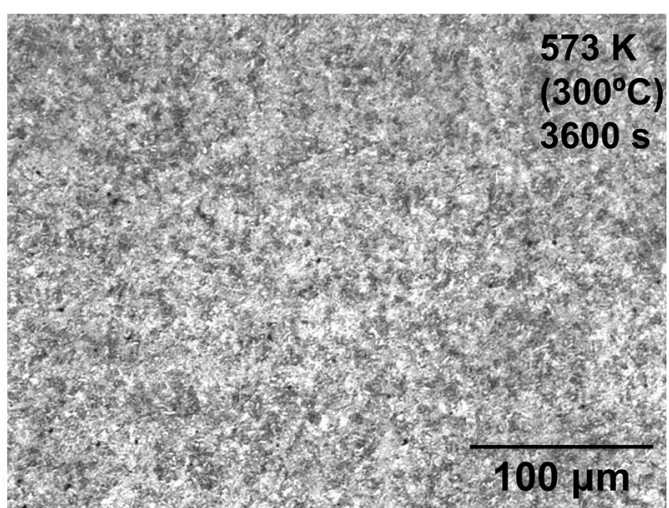

(b)

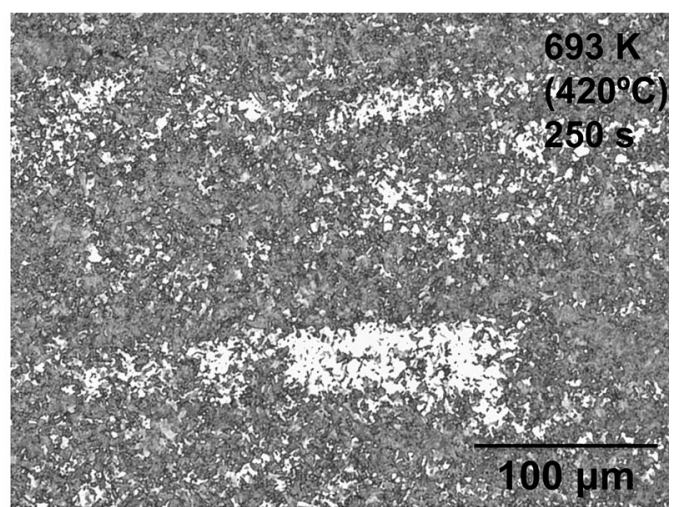

(d)

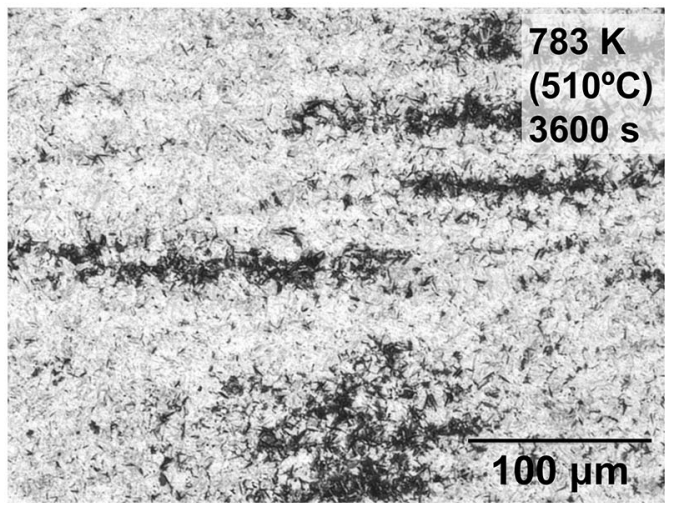

(f)

Fig. 2-Low magnification micrographs showing the microstructure obtained after interrupted isothermal treatments, with the time and temperature indicated in the top right corner of each micrograph. In all cases, dark-etching phase is bainite and white-etching phase is fresh martensite and/or retained austenite. The samples were etched with Nital 2 pct.

dilatometer have been analyzed by means of optical microscopy. Representative examples of the morphologies formed are presented in Figure 2. In order to show the scale at which the segregation occurs, low magnification micrographs are shown.

Bainite was found to form during all heat treatments. The temperature of the isothermal holding determines the microstructure and the final fraction of bainite obtained. It can be observed that bainitic ferrite plates do not nucleate homogeneously at all temperatures; indeed, a banded structure forms at early stages of the transformation. The microstructure becomes more homogeneous at the scales of Figure 2 after $1 \mathrm{~h}$ of isothermal annealing at $573 \mathrm{~K}\left(300^{\circ} \mathrm{C}\right)$. For the higher temperatures, untransformed regions (appearing white in the micrograph) are identified after the transformation ceases [see Figures 1(b) and 2(b)]. It is of particular interest to mention that the sample quenched after 500 seconds at $783 \mathrm{~K}\left(510^{\circ} \mathrm{C}\right)$ exhibited very strong surface relief, which results in the distortion of the polished surface, which appears as gray in Figure 2(e). The differences in the appearance of the bands among the samples could be attributed to the initial position of the dilatometer sample in the hot-rolled bar, from which 


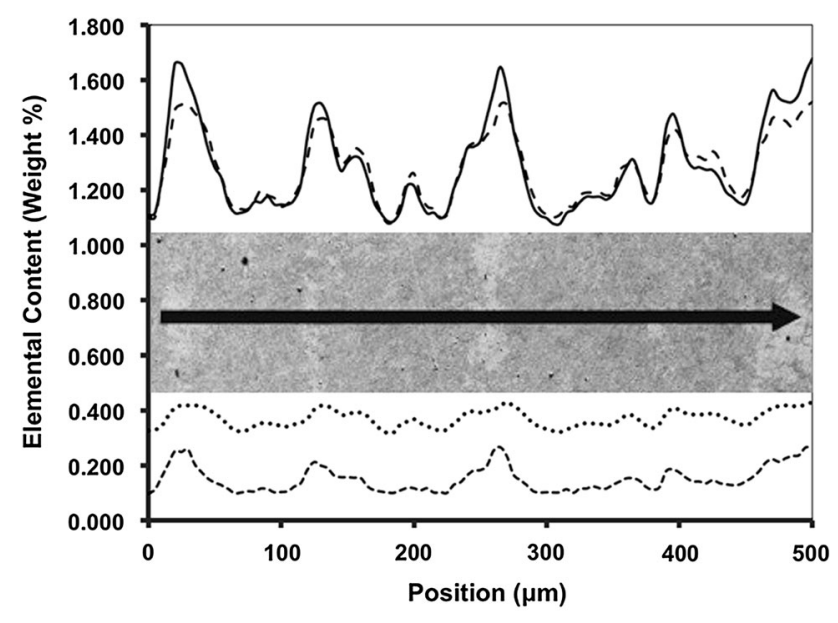

-.... Silicon -Chromium - - Manganese ---Vanadium

Fig. 3-Electron probe microanalysis results of an as-received sample. $\mathrm{Mn}, \mathrm{Cr}, \mathrm{Si}$, and $\mathrm{V}$ are found to form segregated bands. The segregation of these elements follows the same trend and the high segregation areas can be matched with the martensite/austenite regions (white in SEM).

they were taken. The samples that were extracted from a point closer to the surface, where a higher reduction ratio is expected, exhibit strongly linear bands. On the other hand, samples in which the bands show dendritic characteristics, could have been extracted from a position closer to the center of the hot-rolled bar. The banded structure observed indicates chemical segregation of substitutional alloying elements in the examined steel. Electron Probe Micro Analysis was employed to measure the segregation of $\mathrm{Mn}, \mathrm{Cr}, \mathrm{Si}$, and $\mathrm{V}$. The results are illustrated in Figure 3. Since both $\mathrm{Mn}$ and $\mathrm{Cr}$ lower the activity of $\mathrm{C}, \mathrm{Mn}$ - and $\mathrm{Cr}$-rich regions tend to attract $\mathrm{C}$. Therefore, the carbon segregation occurs in the same regions and at the same time of the segregation of substitutional alloy elements. Nevertheless, thermodynamic calculations show that the difference in $\mathrm{C}$ fraction between the high and the low $\mathrm{Mn}, \mathrm{Cr}$ containing region is very small. The obtained value of $\mathrm{C}$ concentration in C-rich and $\mathrm{C}$-poor regions are 0.54 and $0.50 \mathrm{wt}$ pct, respectively, with the average composition being 0.51 wt pct as reported in Table I.

It is evident that all measured alloying elements segregate simultaneously in alternating bands with average width of $150 \mu \mathrm{m}$. From the data obtained by the linear scan presented, $\mathrm{Mn}, \mathrm{Cr}$, and $\mathrm{Si}$ can reach concentrations up to 60 pet higher than the nominal or average composition measured by OES. It was found that the difference in chemical composition was at similar levels in all the samples measured.

For characterization at a smaller scale, SEM was applied on the same samples. The micrographs are shown in Figure 4.

After isothermal treatment for 500 seconds at $573 \mathrm{~K}$ $\left(300{ }^{\circ} \mathrm{C}\right)$, the microstructure consists of bainitic ferrite in plate morphology and cementite particles precipitated within the bainitic ferrite with orientation 55 to $60 \mathrm{deg}$ to the growth direction of the plate. ${ }^{[13]}$ This microstructure typically represents lower bainite. Fresh martensite/ retained austenite was also present around the lower bainite.

After isothermal treatment for 250 seconds at $693 \mathrm{~K}$ $\left(420^{\circ} \mathrm{C}\right)$, the structure of bainite is different. The microstructure consists of sheaves of bainitic ferrite with boundaries indicating edgewise growth, with coarse cementite precipitates. The precipitates do not have specific orientation to the growth orientation of the bainitic ferrite sheaf. Cementite occasionally is found to form a central lamella, toward the growth direction of the bainitic ferrite sheaf, as also reported in Reference 14 in a Cr-rich, high-carbon steel. Fresh martensite and/or retained austenite islands are also identified, which indicates that the bainite reaction was incomplete within the time limit of the experiment, as can be also seen in Figure 1(b).

After isothermal treatment for 3500 seconds at $783 \mathrm{~K}$ $\left(510^{\circ} \mathrm{C}\right)$, the microstructure is banded, with fresh martensite being the dominant phase. In this case, at the very early stages of the transformation, a small fraction of bainitic ferrite forms at the prior austenite grain boundaries in the absence of any carbide precipitation. The morphology of this ferrite is different than the ones found at lower temperatures. The ferrite fraction formed at this temperature is formed at the early stages of the isothermal holding (up to $500 \mathrm{~s}$ ), but the fraction produces macroscopic change in length that is below the analytical resolution of the dilatometer, as observed in Figure 4(b). After ferrite has formed, a dark-etching austenite decomposition product begins to form, initially at the tips of the bainitic ferrite, but at later stages it is also found at other martensite-ferrite boundaries. In the SEM, Figure 4, it was possible to identify that this product has a needle-like morphology with its constituents being ferrite and cementite. The cementite is found in the middle of the needle with ferrite around it, along the needle's growth direction. The needles also form branches, often perpendicular to the growth direction of the main needle. The carbides were also found to have a curved shape, which is attributed to the possible local stacking fault variation, as described in Reference 15.

The presence of retained austenite is difficult to be verified with the optical microscopy or even SEM analysis. In order to verify the presence of retained austenite in the final microstructure, samples of the isothermal treatments were analyzed by means of X-ray Diffraction. The results of the measurements show that in all cases [ $573 \mathrm{~K}, 693 \mathrm{~K}$, or $783 \mathrm{~K}\left(300{ }^{\circ} \mathrm{C}, 420^{\circ} \mathrm{C}\right.$, or $\left.510{ }^{\circ} \mathrm{C}\right)$ ], a limited volume fraction of approximately 2 pct austenite was present.

These results indicate that most remaining austenite transformed into martensite during the final quench after the isothermal treatment but there is a limited fraction of austenite that is stable enough to be retained at room temperature.

\section{DISCUSSION}

The microstructural evidence of banded structures found at short isothermal holding times that become (more) homogeneous as the isothermal holding time becomes longer, needs further discussion. The microstructures produced experimentally raise questions 


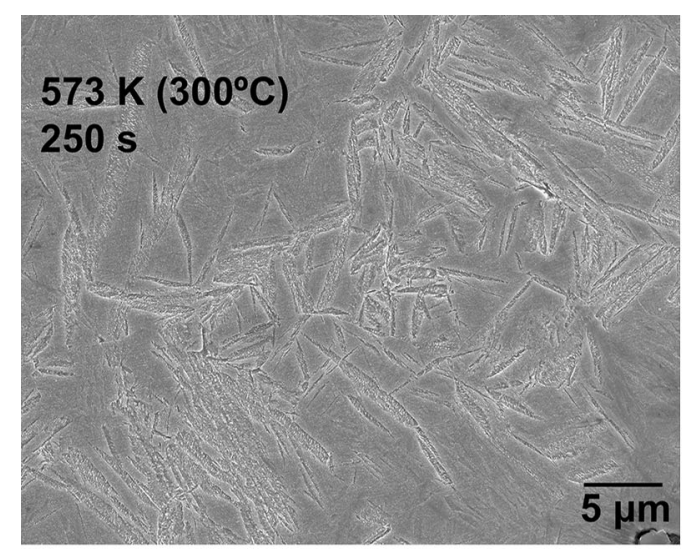

(a)

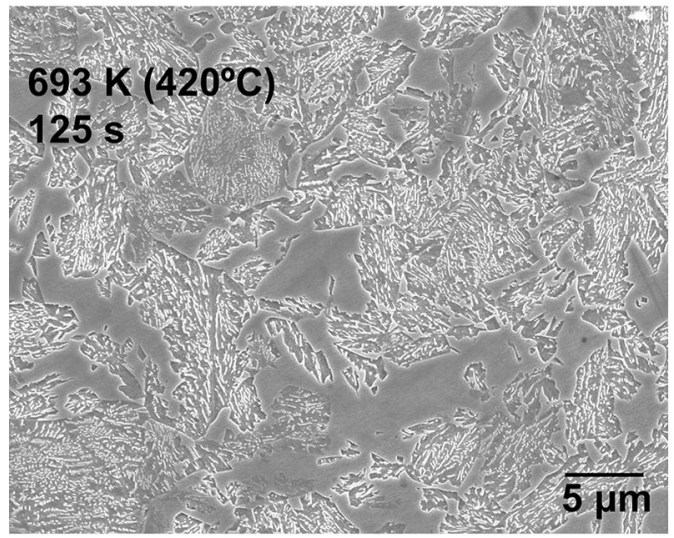

(c)

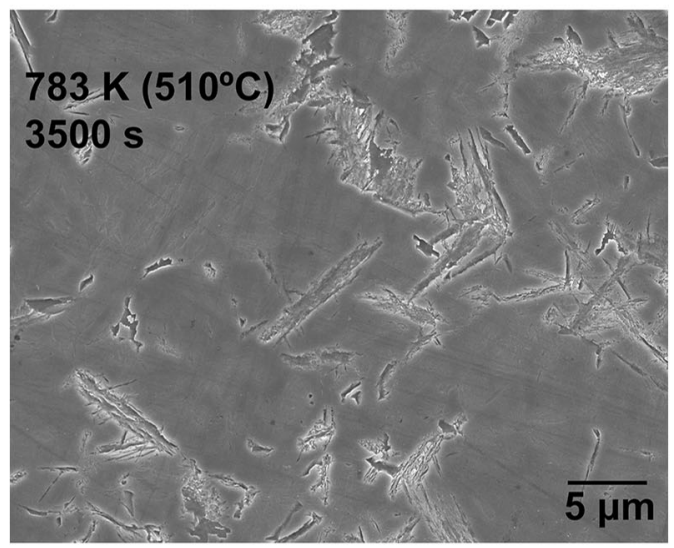

(e)

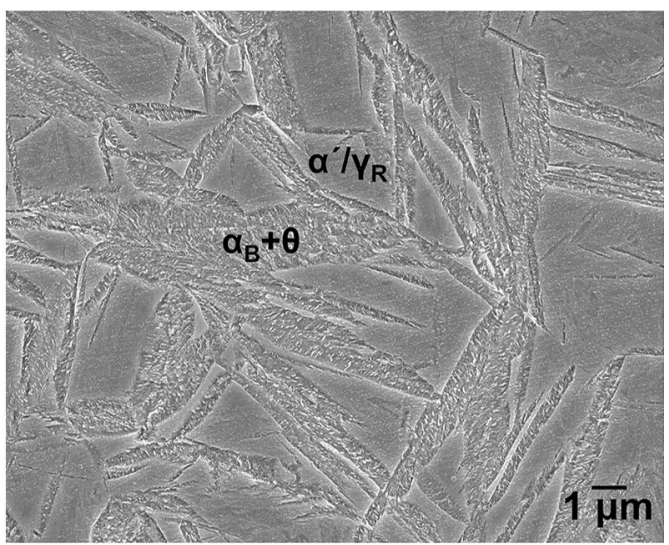

(b)

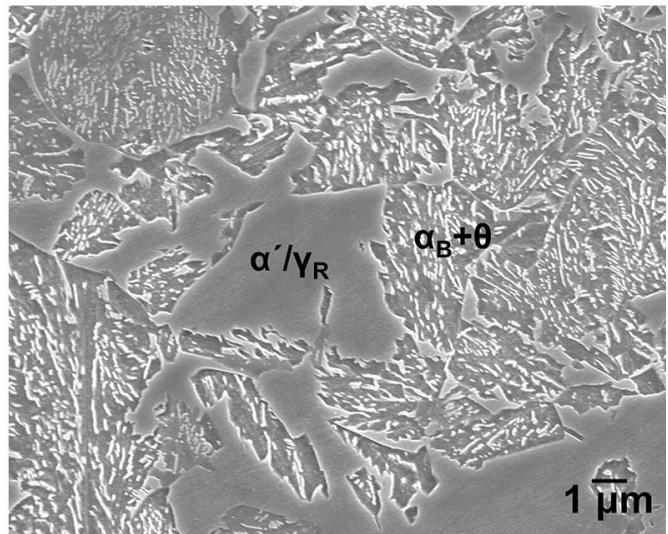

(d)

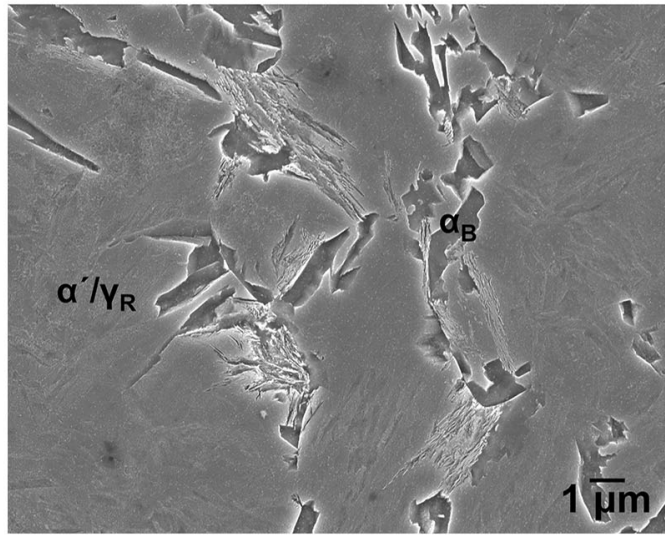

(f)

Fig. 4 - Scanning electron micrographs showing the different bainite morphologies obtained after isothermal holding at different temperatures. The samples were etched with Nital 2 pct.

about the formation mechanism and the nature of bainite transformation. The chemical inhomogeneity will be used as a tool to interpret the evolution of the bainitic transformation in $51 \mathrm{CrV} 4$ steel.

\section{A. Diffusionless Assumption: Driving Force for Nucleation and Nucleation Rate}

Assuming that bainite forms by a diffusionless mechanism, the formation kinetics is determined by the nucleation rate of bainitic ferrite. In the present case, the microstructure analysis for the interrupted samples after short isothermal holding times shows that bainitic ferrite is detected only in the $\mathrm{Mn}-\mathrm{Cr}$-poor regions. In the $\mathrm{Mn}-\mathrm{Cr}$-rich regions, no evidence of bainitic ferrite formation is found. At longer times, especially at lower temperatures [573 $\left.\mathrm{K}\left(300{ }^{\circ} \mathrm{C}\right)\right]$, the bainitic ferrite forms in the whole sample. This change in the microstructure can be attributed to a difference in the formation kinetics of bainitic ferrite between the different regions. 
Following the diffusionless assumption, this difference in the formation kinetics can only be attributed to the difference in the nucleation conditions of bainitic ferrite plates in the regions according to the local chemical composition. One would expect that the nucleation conditions be fulfilled only for the compositions under which bainitic ferrite is found to form experimentally. In order to validate this assumption, the theoretical nucleation conditions for the extreme values of the local composition were calculated.

According to diffusionless theory, bainite is expected to form when two conditions are fulfilled simultaneously. First, the maximum driving force for nucleation $\Delta G_{\mathrm{m}}$ must be higher than the value given by the general nucleation function. Additionally, the driving force for transformation of austenite into ferrite must exceed the energy barrier for bainite, so diffusionless growth can be sustained. The above conditions are summarized as follows:

$$
\begin{gathered}
\Delta G_{\mathrm{m}}<G_{\mathrm{N}} \\
\Delta G^{\gamma \rightarrow \alpha}<-G_{\mathrm{SB}},
\end{gathered}
$$

where both $\Delta G_{\mathrm{m}}$ and $\Delta G^{\gamma \rightarrow \alpha}$ are negative; $G_{\mathrm{SB}}$ is the stored energy of bainite, equal to $400 \mathrm{~J} / \mathrm{mol}$; and $G_{\mathrm{N}}$ is a universal nucleation function. The first of these conditions ensures that nucleation takes place and the second is that the chemical free energy change exceeds the stored energy of bainite. The driving force for nucleation of bainitic ferrite was calculated for different temperatures for both the high and low $\mathrm{Mn}, \mathrm{Cr}$ compositions, as derived from the segregation curve in Figure 3 using Thermo-Calc software. The calculations performed are illustrated in Figure 5. In the temperature range of bainite formation in $51 \mathrm{CrV} 4$, it is evident that the both chemical compositions fulfill both nucleation conditions at low temperatures, while at high temperature, the $T_{0}{ }^{\prime}$ limitation (indicated in Figure 5) for highly segregated chemical composition could explain the incomplete reaction observed. This means that the local chemical composition would allow the formation of bainitic ferrite nuclei at $573 \mathrm{~K}$ both in the Mn-Cr-rich regions and in the $\mathrm{Mn}-\mathrm{Cr}$-poor regions. Thus, we would expect to have a generally homogeneous microstructure at low temperatures. Additionally, the formed nuclei are expected to be evenly distributed in the microstructure. Neither of these expectations could be verified, at the scale detectable by the techniques used.

\section{B. Thermodynamic Calculations: Similarities with High C Steels}

Figure 6 shows the calculated $\mathrm{Fe}-\mathrm{C}$ phase diagram of $51 \mathrm{CrV} 4$ alloy with constant fractions of $\mathrm{Cr}, \mathrm{Mn}$, and $\mathrm{Si}$. For the calculations of Figure 6(a), the minimum values of concentrations of Figure 3 were used, while Figure 6(b) is constructed based on the maximum values. The calculations were performed with ThermoCalc software. The $51 \mathrm{CrV} 4$ alloy can actually behave like hyper-eutectoid steel in regions containing high concentrations of $\mathrm{Cr}$ and $\mathrm{Mn}$, even though the overall

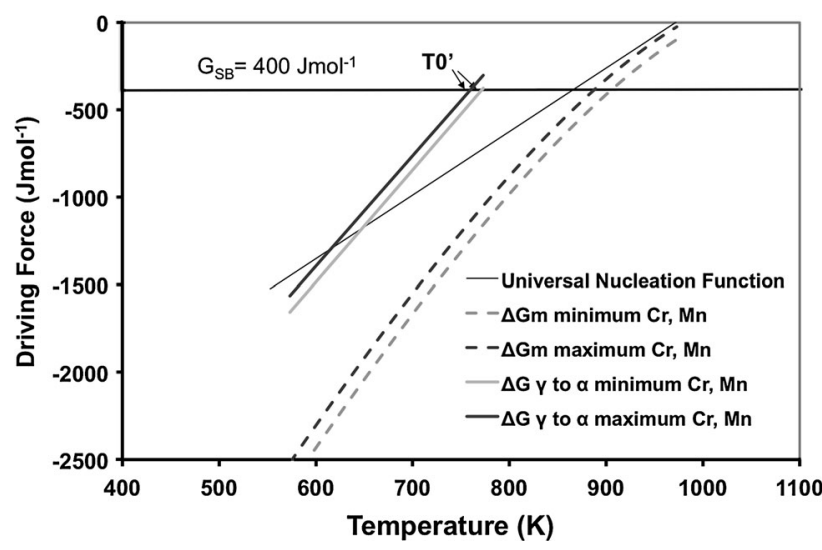

Fig. 5-Composition-dependent driving force $v s$ temperature for diffusionless nucleation and diffusionless growth conditions. $G_{\mathrm{N}}$ is a universal nucleation function.

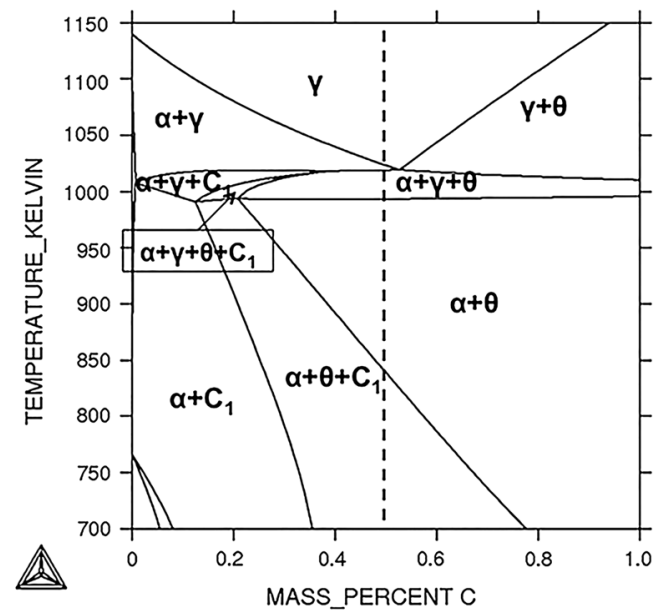

(a)

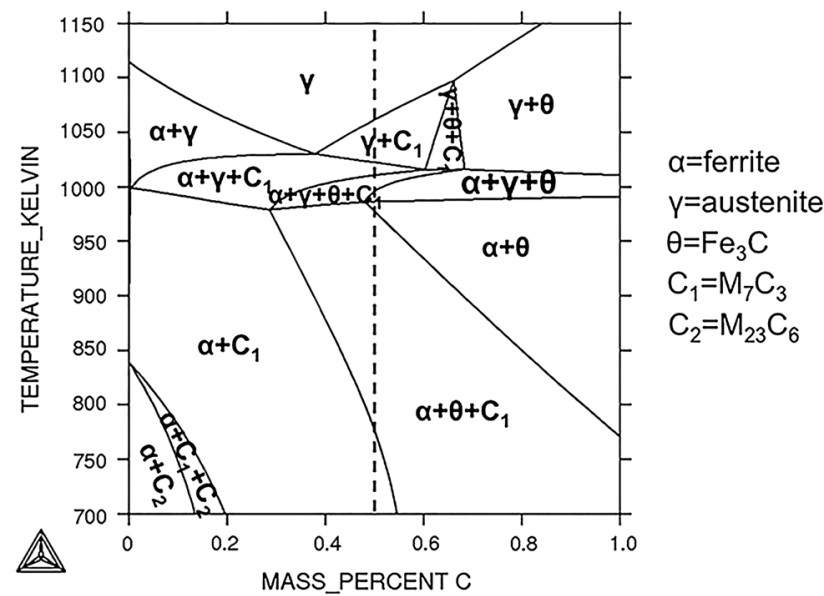

(b)

Fig. 6 - Ortho-Equilibrium phase diagram calculations for the chemical compositions of the high and low concentration bands. Cementite becomes unstable below $713 \mathrm{~K}\left(440^{\circ} \mathrm{C}\right)$ and $\mathrm{Cr}$-rich carbide precipitation is favored. Dashed lines indicate the carbon concentration of $51 \mathrm{CrV} 4$. Calculations were performed by Thermo-Calc software using TCFE5 database. 


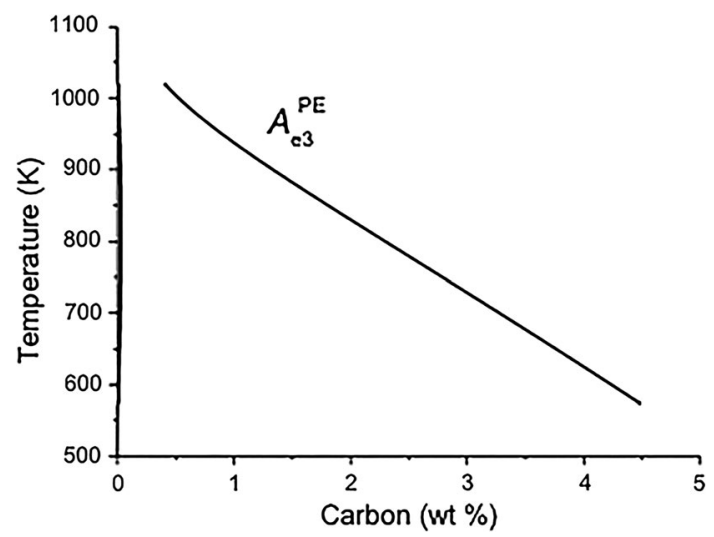

Fig. 7-Quasi-Binary Fe-C para-equilibrium phase diagram for $51 \mathrm{CrV} 4$.

composition is hypo-eutectoid (or near eutectoid), Figure 6 . The fact that $51 \mathrm{CrV} 4$ can behave like a hyper-eutectoid steel explains morphological similarities between this medium-carbon steel and findings reported for bainite in higher carbon steels.

The isopleths of Figure 6 also show that the austenite decomposition under equilibrium in the high and the low segregation regions will be different. In the case of the low segregation chemical composition, the austenite will decompose into ferrite and cementite first and at lower temperatures, below $850 \mathrm{~K}\left(577^{\circ} \mathrm{C}\right)$, also precipitation of $\mathrm{M}_{7} \mathrm{C}_{3}$ is expected. In the case of high $\mathrm{Cr}$ and $\mathrm{Mn}$ segregation chemical composition, the austenite is expected to decompose first into $\mathrm{M}_{7} \mathrm{C}_{3}$ (proeutectoid), with ferrite and cementite forming at lower temperatures.

Bainitic ferrite formation is accompanied by carbon diffusion in the austenite matrix. For high value of the interface mobility, the carbon content in austenite at the interface is given by equilibrium value in austenite at the selected transformation temperature. Figure 7 shows the Fe-C quasi-binary phase diagram calculated under the assumption that the ferrite formation occurs without the partition of the substitutional alloy elements $(\mathrm{Cr}, \mathrm{Mn}$, and $\mathrm{Si}$ ). This constrain equilibrium is called para-equilibrium (PE).

\section{Effect of Carbide Precipitation}

Generally, carbide precipitation during bainite formation leads to enhancement of the overall kinetics of the transformation. This is especially evident when comparing high $\mathrm{Si}$ steels, in which carbide precipitation is inhibited, with lean Si steels, where carbide precipitation takes place.

In the present case, $51 \mathrm{CrV} 4$ contains low $\mathrm{Si}$ content, but it contains $\mathrm{Cr}$ and $\mathrm{V}$, both known to be carbide-forming elements. The carbide-forming elements could affect the carbide precipitation process during bainite formation. The behavior of $\mathrm{Cr}$ during carbide precipitation in the bainite transformation constitutes a topic that is still not completely understood. ${ }^{[16]}$

In order to validate if $\mathrm{Cr}$ is diffusing during carbide precipitation, chemical composition analysis of the
Table III. Average Chemical Composition of Carbides Measured with STEM-EDS in Bainite

\begin{tabular}{lrr}
\hline Temperature & Cr (wt pct) & Mn (wt pct) \\
\hline $573(300)$ & $2.87 \pm 0.1$ & $1.01 \pm 0.05$ \\
$693(420)$ & $1.8 \pm 0.1$ & $1.01 \pm 0.05$ \\
\hline
\end{tabular}

carbides was performed using STEM-EDS. The results show that in the specimen heat treated at $573 \mathrm{~K}$ $\left(300{ }^{\circ} \mathrm{C}\right)$, the carbides are richer in $\mathrm{Cr}$ than the carbides in the specimen that transformed at $693 \mathrm{~K}\left(420^{\circ} \mathrm{C}\right)$, with both values being higher than the matrix composition. The $\mathrm{Mn}$ content is very close to the alloy composition of Table I in all measurements. In Table III, the average $\mathrm{Mn}, \mathrm{Cr}$ contents of the carbides measured are shown for the two cases and Figure 8 shows representative spot EDS analysis points, as observed through the STEM. The enrichment of the carbides in $\mathrm{Cr}$ is a process that requires long-range diffusion of $\mathrm{Cr}$. This is expected to have a negative impact on the overall kinetics of the bainite transformation.

The $\mathrm{Cr}$ contents of the carbides measured by EDS need to be further interpreted. It is shown in Figure 6 that at the temperature range of bainite formation, alloy carbides should form and especially in the case of high segregation chemical composition, cementite is not stable at $573 \mathrm{~K}\left(300{ }^{\circ} \mathrm{C}\right)$. This is only true under the assumption of possible substitutional alloying element partitioning during the transformation. In practice, at low temperature, the transformation of austenite to bainitic ferrite and carbides may proceed without partitioning of substitutional elements (PE). In this case, $\mathrm{Cr}$ should not partition, and only PE cementite should be formed.

Carbides precipitation is expected to occur in austenite at the interface with the bainitic ferrite, where the carbon content is high. For high-carbon content $(>0.8$ wt pct), even under full equilibrium, only cementite is stable (Figure 6). Figure 9 shows the chromium content in a nucleus of cementite formed at $573 \mathrm{~K}$, $693 \mathrm{~K}\left(300{ }^{\circ} \mathrm{C}, 420{ }^{\circ} \mathrm{C}\right)$ as a function of carbon content in the austenite matrix. It is evident that the chromium content in cementite decreases as the carbon content in matrix increases, as also reported in the literature. ${ }^{[12]}$ The calculations were done using the thermo-calc software under the assumption of $\mathrm{Cr}$ partitioning between austenite and cementite. The $\mathrm{Cr}$ content values measured by EDS for the temperature of $573 \mathrm{~K}, 693 \mathrm{~K}$ $\left(300{ }^{\circ} \mathrm{C}, 420{ }^{\circ} \mathrm{C}\right.$ ) imply a difference in the maximum $\mathrm{C}$ content reached during bainite formation at the bainitic ferrite-remaining austenite interface. Further research is performed to better understand this point. Even though the compositional analysis of carbides by EDS in foil specimens can be influenced by the matrix composition, the $\mathrm{Cr}$ content values measured by EDS correspond well to the calculated values of $\mathrm{Cr}$ content in cementite for equilibrium conditions.

Apart from the substitutional elements, during carbide formation diffusion of $\mathrm{C}$ is required, which is taken 


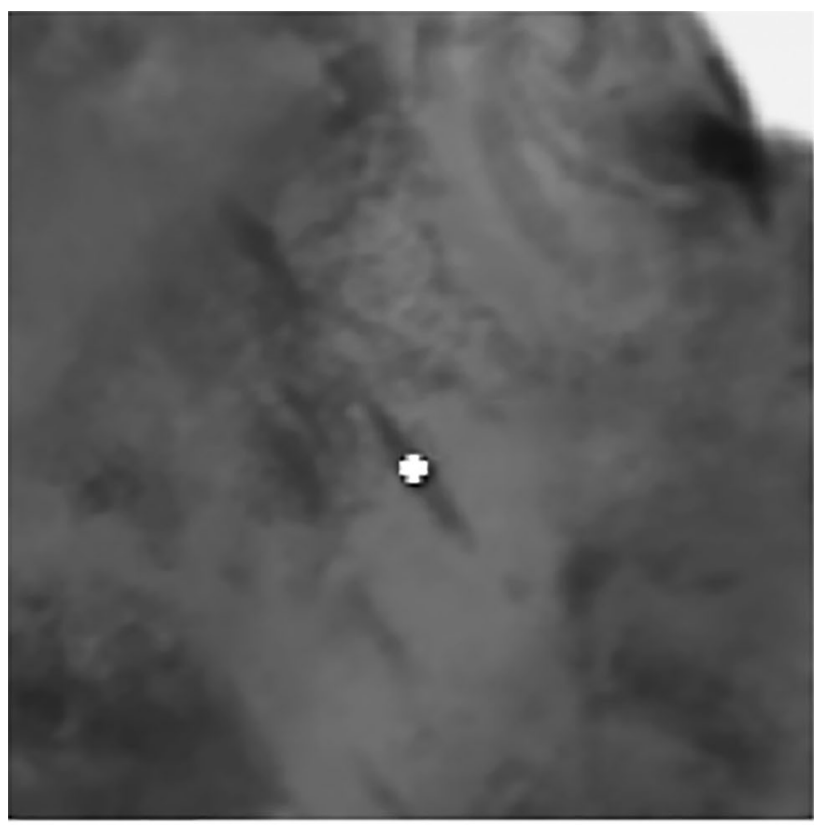

$\longdiv { 2 5 0 \mathrm { nm } }$

(a)

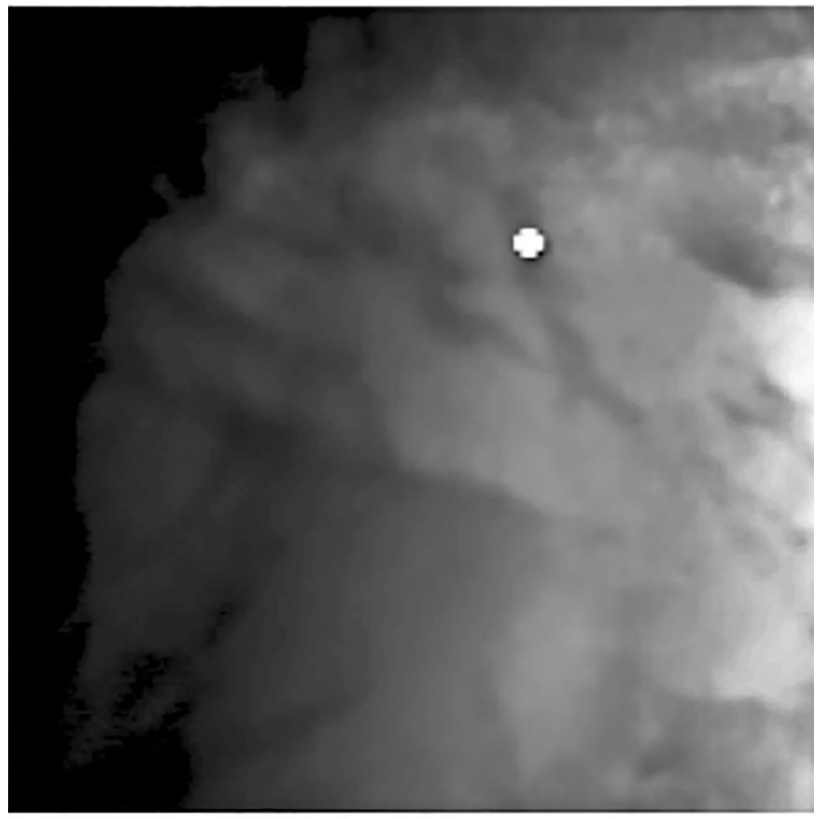

$\longdiv { 2 5 0 \mathrm { nm } }$

(b)

Fig. 8-Scanning Transmission Electron micrographs showing representative spot EDS analysis positions in: (a) lower bainite $[573 \mathrm{~K}$ $\left.\left(300{ }^{\circ} \mathrm{C}\right)\right]$ and $(b)$ upper bainite $\left[693 \mathrm{~K}\left(420^{\circ} \mathrm{C}\right)\right]$.

for granted, as $\mathrm{C}$ is an interstitial atom and its diffusivity is several orders of magnitude higher than the one of the substitutionals, like Cr. During bainite formation, when a plate of bainitic ferrite forms, there is driving force for $\mathrm{C}$ diffusion into the remaining austenite or into the carbides. An important difference between the two possibilities is that when $\mathrm{C}$ diffuses into the remaining

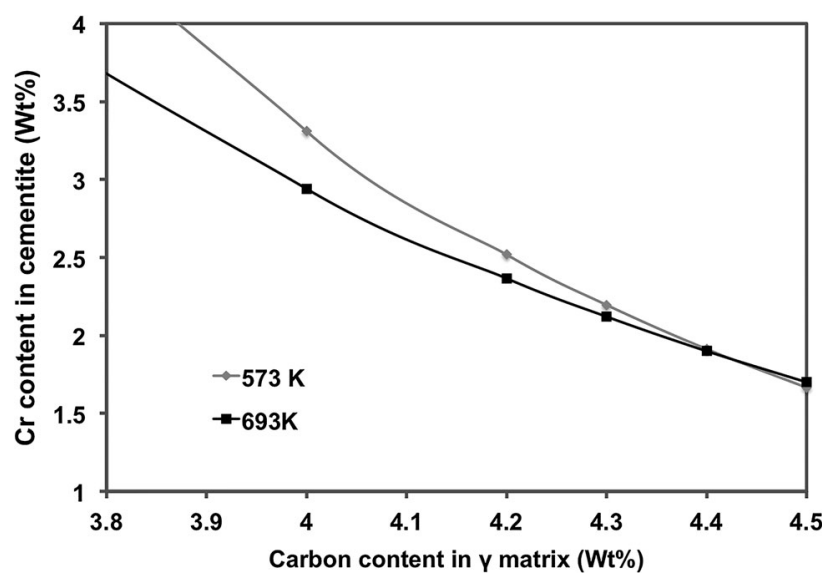

Fig. 9-Equilibrium content of $\mathrm{Cr}$ in cementite with respect to its carbon content.

austenite, the overall driving force for bainite formation reduces, but when it diffuses into the carbides, the driving force increases. As in the present case, carbide precipitation can be retarded because of the $\mathrm{Cr}$ partitioning, $\mathrm{C}$ diffuses partly into the austenite and stabilizes it. The carbon enrichment of the austenite could be detected by the dilatometric signal in the change in length-temperature plot, Figure 1(a). During the final quench, fresh martensite formation begins at different martensite start temperatures. These temperatures decrease as the isothermal holding temperature decreases. Considering that the substitutional alloying elements do not have enough time to diffuse over long ranges during martensite transformation, only the carbon could affect the overall martensite start temperature. The enrichment of the untransformed austenite in $\mathrm{C}$ and its stabilization could provide additional reasons for the local retardation of the bainite transformation.

\section{Inverse Bainite}

If the local composition is hyper-eutectoid in the quasi-binary Fe-C diagram, cementite can become the leading phase in the bainite formation at high isothermal holding temperatures, close to $773 \mathrm{~K}\left(500^{\circ} \mathrm{C}\right)$, which results in the formation of the austenite decomposition product that has been reported first by Kinsman and Aaronson ${ }^{[14]}$ and more recently by Kolmskog ${ }^{[10]}$ as inverse bainite, identified in highcarbon, Mn, $\mathrm{Cr}$ and Mo alloyed steel grades. The dark-etching microstructural constituent found in the present study to form at $783 \mathrm{~K}\left(510{ }^{\circ} \mathrm{C}\right)$ after isothermal holding shows similarities with inverse bainite as not only observed by Kinsman and Aaronson, ${ }^{[17]}$ but also recently by Borgenstam et al. ${ }^{[18]}$ Goldenstein and Cifuentes $^{[15]}$ in their study of austenite decomposition products in a $\mathrm{Cr}$-containing steel mainly above the bay of the TTT diagram have shown that just below the bay temperatures, the decomposition products have a so-called "arborescent" morphology with needles forming branches, which is also identified in the present case. Additionally, the equivalence of the alloy composition to a hyper-eutectoid steel in the high segregation areas 
leads to the suggestion that the microstructure at $783 \mathrm{~K}$ $\left(510{ }^{\circ} \mathrm{C}\right)$ consists of bainitic ferrite (formed at early stages) and inverse bainite (formed at later stages) in a martensitic matrix.

\section{E. Effect of Vanadium}

The 51CrV4 steel was originally designed to be used in the Quenched and Tempered $(\mathrm{Q}+\mathrm{T})$ condition. The intention of the $\mathrm{Cr}$ addition is to increase the hardenability, whereas $\mathrm{V}$ is added to induce a secondary hardening effect during the tempering step. From the thermodynamic calculations for VC precipitation, it results that $\mathrm{VC}$ becomes stable around $1183 \mathrm{~K}\left(910^{\circ} \mathrm{C}\right)$, which is higher than the austenitization temperature. This means that VC is stable throughout the heat treatment and could play a role in stimulating nucleation of bainitic ferrite at the isothermal stage. Apart from that, since $\mathrm{V}$ is altering thermodynamics of the fcc-bcc interaction negligibly, it does not play any other role in the microstructure evolution. By applying an isothermal treatment though, the secondary hardening effect that $\mathrm{V}$ induces during tempering is not exploited as it is during $\mathrm{Q}+\mathrm{T}$.

\section{F. The Role of Chromium-Indications for Diffusional Mechanism}

Based on the observations resulting from the experiments performed in this study, it is suggested that the overall bainite formation kinetics is not only influenced by the nucleation, but are also significantly influenced by the growth of the nucleated bainitic ferrite. The influence of growth on the mechanism of bainite formation leads to the suggestion that the transformation can be diffusional in nature. To further support this suggestion, the behavior of the substitutional elements, and the possible presence of inverse bainite can all be consistently explained by the diffusional theory. Mn and $\mathrm{Cr}$ are both well known to retard the bainite formation, especially at isothermal holding temperatures close to the bainite start temperature, by solute drag. They are also responsible for incomplete transformation. These cases are well reported in the literature. ${ }^{[19]}$ Recently, Chen et al. have performed detail analysis on the solute drag effect caused by the Mn segregation at the $\alpha / \gamma$ interface in Fe-C-Mn alloys containing low fractions of $\mathrm{C}$ and 3.0 wt pet $\mathrm{Mn} .{ }^{[20]}$ In their experiments, they have shown that $\mathrm{Mn}$ retards the bainite formation significantly. In the present case, the Mn chemical composition differences are not large enough to produce such an effect, thus the additional role of $\mathrm{Cr}$ is considered critical for producing the observed microstructures. We consider the role of $\mathrm{Cr}$ to be particularly important in this case because it is found to affect the resulting microstructure differently at high and low isothermal holding temperatures. At high temperatures, near $773 \mathrm{~K}$ $\left(500{ }^{\circ} \mathrm{C}\right)$, growth of bainitic ferrite is almost inhibited It has been suggested that $\mathrm{Cr}$ produces a solute drag effect at the moving interface of bainitic ferrite, which dramatically retards the growth of the plate. ${ }^{[8]}$ At lower temperatures within the bainite formation range, $\mathrm{Cr}$ retards the kinetics of the bainite reaction by partitioning into the carbides. In an inhomogeneous material, as the one studied in the present research, the above-described phenomenon will result in a banded microstructure in the early stages of the transformation, but if enough time in the isothermal holding step is allowed, the microstructure will eventually become homogeneous. From the experimental observations, this is true for isothermal holding temperatures close and above the martensite start temperature, but when the isothermal holding temperature becomes higher, still incomplete reaction is evident, which is then attributed to the solute drag effect.

\section{CONCLUSIONS}

An isothermal treatment was applied to $51 \mathrm{CrV} 4$ steel grade as an alternative to quenching and tempering. The bainite formation mechanism was studied and discussed. By performing dilatometer tests and microscopy analysis, the following conclusions are found:

1. Homogeneous lower bainitic microstructures at holding temperatures close and above the martensite start temperature can be produced, even though it contains chemical segregation when produced industrially.

2. At higher temperatures, significant retardation or the transformation was observed, leading also to incomplete reaction. Incomplete reaction was observed mainly at the bands of the material where the concentration of substitutional alloying elements was high due to segregation.

3. It is suggested that $\mathrm{Cr}$ retards the bainite formation in two ways, depending on the isothermal holding temperature. At high temperatures, close to the bainite start temperature, $\mathrm{Cr}$ retards the growth of the nucleated bainitic ferrite by retarding the interface mobility (solute drag effect). On the other hand, at temperatures below $693 \mathrm{~K}\left(420{ }^{\circ} \mathrm{C}\right), \mathrm{Cr}$ partitions into the carbides, a process requiring long-range diffusion. A certain fraction of the rejected $\mathrm{C}$ from the newly formed bainitic ferrite can diffuse into the residual austenite, before the rest is consumed in the carbide precipitation. The stabilization of the austenite leads to an overall retardation of the bainitic transformation at isothermal holding temperatures close to and above martensite start temperature.

4. Bainite formation kinetics cannot be solely explained by the bainitic ferrite nucleation kinetics, and it is evident that it is closely linked to the bainitic ferrite growth kinetics. Considering also the effect of growth in the kinetics, banded structures appearing at the early stages of the transformation that become homogeneous in the end of the treatment can be consistently explained.

5. Inverse bainite was found to form at $783 \mathrm{~K}\left(510^{\circ} \mathrm{C}\right)$, attributed to the high local $\mathrm{Cr}$ segregation.

6. All the above-described observations lead to the suggestion that the bainite formation can be 
described by the diffusional approach in this type of alloys.

7. The vanadium addition in this grade does not influence the bainitic transformation. Vanadium carbides form at temperatures within the austenite stability region, and are therefore stable at the isothermal transformation temperatures.

\section{ACKNOWLEDGMENTS}

This research was carried out under the project number M22.12.476 in the framework of the Research Program of the Materials innovation institute (M2i) (www.m2i.nl). The authors would like to thank Mr. R. Huizenga and Mr C. Kwakernaak from the Surfaces \& Interfaces group of TU Delft for performing the XRD and EPMA measurements, respectively. Dr. T. Sourmail from ASCO Metal is acknowledged for performing the interrupted dilatometry experiments. The authors would like to thank Professor Fourlaris, Dr. Tsakiridis, and Dr.-ing S. Papaefthymiou of National Technical University of Athens for the STEM-EDS measurements.

\section{OPEN ACCESS}

This article is distributed under the terms of the Creative Commons Attribution 4.0 International License (http://creativecommons.org/licenses/by/4.0/), which permits unrestricted use, distribution, and reproduction in any medium, provided you give appropriate credit to the original author(s) and the source, provide a link to the Creative Commons license, and indicate if changes were made.

\section{REFERENCES}

1. Y. Tomita and K. Okabayashi: Metall. Trans. A, 1984, vol. 15, pp. $2247-49$

2. T.Y. Kim and H.K. Kim: Mater. Sci. Eng. A, 2013, vol. 580, pp. 322-29.

3. A. Hultgren: Trans. ASM, 1947, vol. 39, p. 815.

4. M. Hillert, Royal Institute of Technology, Stockholm, 1960.

5. M. Hillert: Metall. Mater. Trans. A, 1994, vol. 25A, pp. 1957-66.

6. W.T. Reynolds, S.K. Liu, F.Z. Li, S. Hartfield, and H.I. Aaronson: Metall. Trans. A, 1990, vol. 21, pp. 1479-91.

7. W.T. Reynolds, F.Z. Li, C.K. Shui, and H.I. Aaronson: Metall. Trans. A, 1990, vol. 21, pp. 1433-63.

8. H.I. Aaronson, W.T. Reynolds, Jr, and G.R. Purdy: Metall. Mater. Trans. A, 2004, vol. 35A, pp. 1187-1210.

9. C. Zener: Trans. ASM, 1946, vol. 167, pp. 550-95

10. T. Ko and S.A. Cottrell: J. Iron Steel Inst., 1952, vol. 172, p. 307.

11. H.K.D.H. Bhadeshia and D.V. Edmonds: Acta Metall., 1980, vol. 28 , pp. 1265-73.

12. H.K.D.H. Bhadeshia, IOM Communications Ltd, London, 2001.

13. M.Y. Tu, C.A. Hsu, W.H. Wang, and Y.F. Hsu: Mater. Chem. Phys., 2008, vol. 107, pp. 418-25.

14. P. Kolmskog, PhD Thesis Royal Institute of Technology (KTH) Stockholm, 2013.

15. H. Goldenstein and J.A. Cifuentes: Metall. Mater Trans A, 2006, vol. 37A, pp. 1747-55.

16. H. K. D. H. Bhadeshia, Mater Sci Eng: A, 1999.

17. K.R. Kinsman and H.I. Aaronson: Metall. Mater. Trans. A, 1970, vol. 1A, pp. 1485-88.

18. A. Borgenstam, P. Hedström, M. Hillert, P. Kolmskog, A. Stormvinter, and J. Ågren: Metall. Mater. Trans. A, 2011, vol. 42A, pp. 1558-74.

19. H.I. Aaronson, W.T. Reynolds, G.J. Shiflet, and G. Spanos: Metall. Trans. A, 1990, vol. 21, pp. 1343-80.

20. H. Chen and S. Van Der Zwaag: Acta Mater., 2014, vol. 72, pp. $1-12$. 